\title{
A transição para o consumo sustentável em contextos de baixa renda: visão geral, barreiras e contradições
}

The transition towards sustainable consumption on low income contexts: overview, barriers and contradictions

GARCIA, Aline Müller; mestranda; Universidade Federal do Paraná UFPR

eilan.muller@gmail.com

SANTOS, Aguinaldo dos; Ph.D; Universidade Federal do Paraná UFPR

asantos@ufpr.br

\section{Resumo}

Este artigo apresenta um estudo sobre os hábitos de consumo que impactam diretamente no consumo de água e energia com ênfase nos contextos de baixa renda, mais precisamente nas Habitações de Interesse Social (HIS). É apresentada uma visão geral sobre a transição para um consumo mais sustentável, considerando alguns estudos realizados no Brasil e em outros países que possuem características econômicas semelhantes. São explorados no artigo hábitos relacionados principalmente a limpeza e higiene, com destaque para o hábito de tomar banho no Brasil e sobre como ele foi construído socialmente. A partir de revisões da literatura qualificada, são identificados os limites, barreiras e contradições para um consumo mais sustentável entre populações de baixa renda. Dessa forma, o objetivo do artigo é apresentar informações de base que devem ser consideradas no design de produtos e serviços sustentáveis voltados aos usos da água e energia no ambiente doméstico das HIS.

Palavras Chave: consumo sustentável; baixa renda; banho.

\begin{abstract}
This paper presents a study about the consumption habits that directly impact water and energy consumption with emphasis on low-income contexts, more precisely on Social Housing. An overview about the transition towards sustainable consumption is presented, considering some research carried out in Brazil and other countries that have similar economic characteristics. Habits related mainly to cleanliness and hygiene are explored in the paper, especially the habit of bathing in Brazil and how it was built socially. From the reviews of qualified literature, the limits, barriers and contradictions for a more sustainable consumption among low income populations are identified. Thus, the objective of the article is to present base information that should be considered in the design of sustainable products and services aimed at the use of water and energy in the domestic environment of Social Housing.
\end{abstract}

Keywords: sustainable consumption; low-income; bath. 


\section{Introdução}

Os hábitos de consumo das sociedades estão diretamente relacionados com a forma com que as pessoas veem o mundo e com o meio social que elas estão inseridas. O termo "consumo sustentável" diz respeito a inovações tecnológicas, mudanças individuais nas escolhas de consumo e além disso, considera ações coletivas, mudanças econômicas e institucionais para possibilitar que o consumo se torne mais sustentável. Trata-se de uma meta a ser atingida, que considera tanto os padrões de utilização dos recursos como a quantidade de recursos utilizada pelas pessoas (MEC, 2005). Por outro lado, o termo "Habitação de Interesse Social (HIS)" trata-se da denominação de programa governamental que visa a construção habitacional para famílias de baixa renda. 0 objetivo do programa é subsidiar o financiamento de habitações próprias para famílias que recebem até três salários mínimos (CAIXA, 2018). Este artigo aborda as relações entre estes hábitos de consumo e a sustentabilidade, considerando os fatores que motivam os hábitos, como significados culturais e sociais do consumo em contextos de baixa renda.

Em países em desenvolvimento, como o Brasil, prover acesso aos bens de consumo e a qualidade de vida às pessoas de baixa renda, e ao mesmo tempo possibilitar um consumo sustentável é um desafio. Shäfer, Jaeger-Erben e Santos (2011) falam sobre a possibilidade de um leapfrogging, no qual as classes sociais emergentes poderiam dar um salto em direção ao consumo sustentável, ao invés de adotar os estilos de consumo dos países industrializados. Os autores sugerem que para tornar possível esse salto é necessário saber mais sobre os hábitos de consumo atuais e as aspirações futuras das populações de baixa renda. Dessa forma, este artigo apresenta alguns estudos realizados no Brasil e em países com características econômicas semelhantes, para que assim seja possível identificar caminhos e aberturas para um salto direto a formas de consumo mais sustentáveis.

Instigar mudanças de forma coletiva é uma meta desafiadora diante das diferenças de estilos de vida encontradas nas sociedades atualmente. Cardoso (2012) chama a atenção para as diferenças entre os modos de estar no mundo apresentados por pessoas que compartilham os mesmos aspectos culturais. Enquanto algumas estão engajadas em realizar mudanças sociais e ambientais, modificando seu comportamento e estimulando outros a fazerem o mesmo, outras pessoas continuam poluindo, sujando e dificultando o processo de transição para a sustentabilidade (ibidem). Desta forma é importante considerar as similaridades e as diferenças nos comportamentos das pessoas, para isto, é necessário compreender profundamente como são formados os seus hábitos de consumo.

O consumo realizado dentro dos lares pode ter grandes implicações para a sustentabilidade. Para Barbosa e Veloso (2014) um dos vetores mais significativos para gerar impactos ambientais negativos diz respeito ao consumo cotidiano, sendo que essas práticas estão relacionadas a especificidades históricas, culturais e sociais. As autoras destacam que "as práticas brasileiras de consumo interno, tais como comer e cozinhar, higiene pessoal, limpeza e outras, ainda estão longe de serem sustentáveis; na verdade, muitas delas são profundamente prejudiciais para o meio ambiente" (BARBOSA, VELOSO, 2014 p. 166). Os padrões de limpeza e higiene, com destaque àqueles relacionados ao hábito de tomar banho são destacados neste artigo, como forma de exemplificar como os significados sociais se relacionam com o consumo e consequentemente com a sustentabilidade.

Este artigo também trata dos limites e contradições para que o consumo sustentável seja 
possível. Estes fatores podem estar relacionados tanto aos processos históricos e culturais, quanto a estilos de vida contemporâneos, afastamento do ser humano da natureza e exaltação da vida urbana. A industrialização e posteriormente a propaganda e o marketing também têm seu papel quando atuam de forma a incentivar o consumo sem considerar os limites do planeta. Estas questões serão aprofundadas neste artigo. Os limites e contradições também são apresentados como forma de demonstrar quais aspectos precisam ser superados na busca por formas de consumo mais sustentáveis.

Assim tem-se por objetivo neste trabalho mostrar como hábitos cotidianos, principalmente no contexto de pessoas de baixa renda residentes em países de economia emergente, se relacionam e tem impactos ambientais, sociais e econômicos. Utilizou-se como método a revisão de literatura, sendo que este artigo corresponde aos estudos de uma dissertação de mestrado. Apresenta-se assim uma visão geral sobre estudos acerca de hábitos de consumo e baixa renda e uma reflexão sobre a importância de considerar-se os significados sociais e culturais neste processo. Utiliza-se como exemplo práticas relacionadas a higiene e limpeza, com destaque para as atividades relacionadas ao banho. Também são abordadas algumas contradições, limitações e barreiras para um consumo mais sustentável.

\section{Visão Geral do consumo em contextos de baixa renda}

Foram verificadas na literatura algumas pesquisas voltadas a compreensão dos hábitos de consumo em contextos de baixa renda. Selecionou-se algumas pesquisas que trazem dados interessantes no Brasil e em outros países de contexto semelhante. Essas pesquisas ajudam a compreender convergências entre pessoas que vivem em situações sociais semelhantes e as conexões de seus hábitos com as questões ambientais. Dessa forma é possível perceber as relações entre os fatores sociais e ambientais que envolvem a sustentabilidade.

Barbosa (2011) realizou pesquisa quantitativa com 3.000 entrevistados, pertencentes a diferentes classes sociais, com o objetivo de compreender algumas questões sobre percepções de sustentabilidade. A autora procurou compreender o quanto as pessoas sabiam sobre a crise ambiental atual, se elas, de fato sabem o que é "consumo responsável" e se estão incorporando medidas sustentáveis em seus cotidianos. Mesmo para os conceitos mais conhecidos como "orgânico" e "certificação ambiental" as pessoas que disseram conhecer muito bem, ou conhecer bem, não passaram dos 30\%. Sendo que em outros critérios menos conhecidos como "emissões de carbono", "comércio justo" e "ambientalmente amigável" as pessoas que disseram conhecer bem ou muito bem, não passaram de $8 \%$. Neste estudo a questão da classe social também foi muito relevante, pois $43 \%$ dos entrevistados pertencentes a classe baixa ou média baixa disseram não compreender o que é sustentabilidade. Pessoas de classes mais altas apresentaram uma compreensão maior sobre os conceitos, porém entre as pessoas mais pobres a compreensão sobre a importância das mudanças de atitudes era maior. Isto se deve ao fato das famílias mais pobres precisarem utilizar mais medidas de economia de recursos, enquanto os mais abastados financeiramente não precisam ter essas preocupações. Sobre critérios de idade percebeu-se que usuários entre 55 a 65 anos estão mais preocupados com economia de água e energia, adotando algumas atitudes como fechar a torneira ao escovar os dentes e não depositar óleo na pia da 
cozinha. As idades que demonstraram maior variedade nos hábitos de mudança foram entre 41 a 65 anos (BARBOSA, 2011).

Chickwech, Stanton e Fletcher (2017) relatam pesquisa qualitativa com abordagem etnográfica realizada com famílias de baixa renda do Zimbábue. A pesquisa se concentrou nos hábitos de alimentação e higiene pessoal e procurou avaliar como acontecem as decisões de compra por produtos relacionados, nestas famílias. A família ainda é um importante fator que influencia hábitos e comportamentos, principalmente em contextos de baixa renda, onde a família nuclear, composta por pai, mãe e filhos é estendida incluindo muitas vezes vários outros parentes. Assim, os produtos adquiridos por um membro da família serão utilizados por todos, de modo que os autores concluíram que a tomada de decisão nestes casos, é coletiva.

Carrete et al. (2012) realizaram estudo etnográfico com 15 famílias de baixa renda que vivem em 4 diferentes regiões do México. O objetivo do estudo foi identificar os fatores que motivam escolhas sustentáveis entre estas pessoas. Os autores perceberam que as desmotivações estavam relacionadas a três fatores: confusão, confiança e credibilidade. O consumo mais econômico de recursos era sempre associado a tradições de poupança, sendo que as famílias não apresentavam preocupações com questões referentes a sustentabilidade. Assim, os autores defendem que para incentivar um consumo mais sustentável é necessário relacionar atitudes ambientalmente positivas a benefícios pessoais que os indivíduos possam ter, principalmente por se tratar de pessoas que já possuem uma série de restrições de consumo. É aconselhada a adoção de esforços colaborativos para facilitar a adoção e a compreensão de práticas em prol da sustentabilidade, como oferecer produtos e serviços a preços acessíveis a essas pessoas (CARRETE, et al., 2012).

Em pesquisa quali-quantitativa realizada em Habitações de Interesse Social da cidade de Campo Grande - MS, com famílias que possuíam renda de até três salários mínimos, Paulo et al. (2012) verificaram os hábitos de consumo relacionados a água e energia. Sendo que o hábito de tomar banho mais de uma vez por dia acontecia em $80,7 \%$ das famílias entrevistadas. Sobre ações para economizar água e energia, 91, 4\% disseram que fecham a torneira ao ensaboar a louça, 83,1\% fecham a torneira enquanto escovam os dentes e $60,5 \%$ fecham a torneira enquanto se ensaboam durante o banho. Somente $1,6 \%$ dos entrevistados afirmam tomar banhos rápidos como medida de economia. De acordo com a percepção dos usuários sobre seu consumo, 53,8\% acham que lavar roupas é a atividade que mais consome água, sendo que somente $26,6 \%$ acreditam que é o banho (PAULO, et al.,2012). Nesta pesquisa também é possível perceber que a preocupação com a economia motiva a gestão dos recursos, porém estes não são os únicos fatores que determinam os hábitos de consumo. Mesmo buscando economia, poucos usuários estavam dispostos a tomar banhos rápidos, embora os mesmos usuários estivessem dispostos a adotar outras medidas de redução do consumo.

Assim, integração da sustentabilidade nos critérios de consumo não pode ser associada tão somente a níveis de renda. De fato, em uma survey sobre hábitos de consumo de alimentos, aplicada na cidade de Curitiba-PR, Shäfer, Jaeger-Erben e Santos (2011), identificaram cinco clusters de consumidores principais:

- Os tradicionais: correspondem $28 \%$ da amostra. Sendo que $77 \%$ são mulheres, alta porcentagem de pessoas de meia idade, vivem em casas/apartamentos grandes, $43 \%$ deles envolvidos em alguma organização social, níveis educacionais mistos. Preferem ter uma horta em casa ou comprar produtos em feiras e cooperativas.

- Os materialistas: correspondem a $22 \%$ dos usuários entrevistados. Desses, $53 \%$ possuem menos de 30 anos, metade deles ganha menos que um salário mínimo, 20\% 
possui educação básica incompleta, 57\% trabalham em serviços técnicos ou básicos, $45 \%$ vivem em pequenos apartamentos, $16 \%$ são divorciados (maior percentual da pesquisa). A maioria deles diz não estar satisfeita com seus eletrônicos, desejam obter uma casa maior e possuem pouco interesse por questões políticas.

- Os indiferentes: correspondem a $21 \%$ dos entrevistados. Sendo que $53 \%$ deles são homens, metade deles não tem filhos, porém é a maior média da pesquisa sobre número de crianças no lar, educação mista, $18 \%$ possuem celular de segunda mão (18\%). Também é o grupo com o menor percentual de pessoas socialmente envolvidas (21\%). Não se importam muito com investimentos em educação das crianças e nem com questões políticas. Possuem pouco interesse por hortas, viagens, e produtos que possam ser personalizados.

- Os privilegiados: correspondem a $20 \%$ da amostra da pesquisa. $51 \%$ são homens, mais da metade deles tem menos de 30 anos, possuem a maior renda da amostragem, $29 \%$ possui ensino superior completo e um terço está cursando a universidade. $75 \%$ deles não possuem filhos, $80 \%$ possui computador, $90 \%$ celular e $74 \%$ internet banda larga. Gostam de sair com os amigos, praticam esportes para a saúde, informam-se por meio da internet e um terço é envolvido socialmente.

- Os pós-materialistas: correspondem a 9\% da amostragem. 33\% possuem mais de 50 anos e $30 \%$ menos de 30 anos. Formação técnica e superior são predominantes. Baixas e médias rendas, grandes números de crianças no lar, vivem em espaços relativamente pequenos por pessoa e $39 \%$ deles não possuía acesso a internet. Preferem produtos que eles mesmos possam fazer, ajudam outros na reforma de suas casas, $48 \%$ está engajado em algum grupo, possuem interesses políticos. Também preferem produtos regionais e atualizáveis, não se importam em utilizar móveis e produtos de segunda mão. Desejam uma casa maior e gostariam de ter horta e jardim e também gostam de sair e viajar.

Em análise, os autores verificam que o maior potencial a uma mudança significativa está nas pessoas classificadas como pós-materialistas, por estarem mais abertas a um consumo sustentável. Os consumidores tradicionais também podem ser envolvidos pois possuem interesses em relação à economia de recursos e alimentação saudável. Os privilegiados, possuem recursos financeiros e posições influentes, estão nos grupos sociais que influenciam comportamentos, por isso é muito importante criar estratégias para engajá-los sustentavelmente. Porém os perfis materialistas e indiferentes precisam ser envolvidos de forma indireta, pois estes grupos possuem níveis baixos de consumo e aspiram a uma vida nos padrões de consumo das classes altas (SCHÄFER, JAEGER-ERBEN, SANTOS, 2011). É possível observar que a relação com a renda embora influencie, não é a única questão que interfere nos comportamentos de consumo. Os perfis identificados no estudo demonstram a importância dos aspectos sociais e culturais de forma individualizada.

O consumo contribui na organização de uma ordem social que mostra as divisões, categorias e classificações existentes nas sociedades. $O$ indivíduo consome para dizer algo sobre ele mesmo, quem ele é, de onde ele veio. Assim, os bens de consumo podem ser usados tanto para incluir quanto para excluir. Por exemplo, a pobreza não é apenas a falta de posses, ela significa exclusão em um fluxo de eventos que se dão por meio do consumo. E o estilo de consumo é uma forma de mostrar status, sendo que os bens são instrumentos de ascensão, participação e exclusão social (SLATER, 2002). Assim, para alcançar soluções efetivas para um consumo sustentável é necessário 
considerar os aspectos socioculturais como um dos fatores determinantes da forma com que as pessoas consomem produtos e serviços.

Um caminho para alcançar o consumo sustentável é que as mudanças neste sentido aconteçam em paralelo às mudanças nas práticas culturais. Valores como riqueza e boa vida precisam ser reformulados para normalizar práticas e hábitos que envolvem valores, crenças e símbolos, que guiarão novos estilos de vida. Para isto acontecer, é necessária uma ação conjunta entre pessoas, empresas, ONGs e governos, além de líderes capacitados e normas institucionais para a disseminação dessas práticas. Porém, são necessárias também pesquisas para criação de alternativas que de fato solucionem os paradigmas atuais de consumo e sustentabilidade (O'ROURKE, LOLLO, 2015).

De acordo com os estudos apresentados, é possível perceber que embora conhecimento sobre práticas sustentáveis sejam mais comuns em famílias com maiores rendas, a questão do comportamento de consumo está mais relacionada ao perfil de consumo. Também é possível identificar que a economia de recursos interessa as populações de baixa renda por acarretar em reduções de taxas. Porém, estes consumidores estão dispostos a adotar hábitos de redução somente em algumas atividades, isto se deve a questões sociais e idealizações estéticas dos significados do bem-estar.

\section{Limpeza, higiene e o hábito de tomar banho}

A limpeza e a higiene assumiram significados importantes para a sociedade atual. Desde 1860, com os trabalhos de Pasteur e Lister sobre as teorias microbianas, a sujeira passou a ser relacionada aos germes transmissores de doenças. Então, a partir da década de 1890 hábitos de higiene passaram a ser ensinados nas escolas e eram defendidos por agentes de saúde, escoteiros e outros profissionais (FORTY, 2007).

No que se refere a limpeza e higiene pessoal no Brasil, a água tem papel central. Enquanto produtos de limpeza industrializados podem ajudar no processo de limpeza, a água é um item básico e fundamental. Barbosa e Veloso (2014) destacam que limpar sem a água é considerada uma limpeza suja, e é importante que essa água seja limpa e tratada, mesmo onde a sujeira é pesada. As pessoas ainda têm receio de fazer o reuso de águas, mesmo para fins não nobres como a limpeza. O brilho também é um indicador utilizado para avaliar os padrões de limpeza das pessoas. Mesmo famílias pobres, residentes em comunidades marginalizadas, como na pesquisa etnográfica realizada por Barbosa (2004), demonstram essa preocupação em indicar que seus utensílios, piso e outros objetos estão de fato limpos. O desafio está em projetar soluções que contribuam para modificar os hábitos sem deixar de considerá-los (os que envolvem alto consumo) como uma barreira, que não pode ser ignorada.

Douglas (2010) sugere que anseios relacionados a poluição surgem em uma sociedade, quando seus marcadores de passagem são ameaçados, ou quando as noções de moralidade de uma cultura estão fragilizadas. Para Forty (2007) as causas sociais que impulsionaram a preocupação com a sujeira estão relacionadas a ascensão política das camadas sociais mais pobres. $\mathrm{O}$ autor sugere que isto indica o temor da classe média de perder o seu poder político. Sendo que dentre os argumentos para a implantação de medidas de higiene, além da saúde, estimulava-se um sentimento de culpa e ansiedade em relação a sujeira, difundida entre os que possuíam menos recursos. Barbosa e Veloso (2014) destacam preocupações com a sujeira verificadas em estudos 
etnográficos com populações de baixa renda, "sou pobre, mas sou limpa", diziam algumas das mulheres donas de casa entrevistas pelas autoras, pois sentiam que sua reputação moral dependia da qualidade da limpeza de seus filhos e de suas casas.

Os padrões do que é considerado limpo (no caso da limpeza das casas, roupas e da própria higiene pessoal) e fresco (no caso dos alimentos) é baseado em uma lógica cultural que Barbosa e Veloso chamam de "lógica da poluição". Esses padrões determinam como devem ser realizados os procedimentos de limpeza, que desconsideram fatores ambientais como o consumo de água eletricidade e produtos de limpeza. As autoras destacam que "tais lógicas ignoram grandemente a questão da sustentabilidade, porque o hábito e a rotina tornaram comum agir deste modo, não sustentável" (BARBOSA, VELOSO, 2014 p. 167). Com o aumento do acesso a recursos básicos, estes comportamentos se tornam mais frequentes, mesmo em populações menos favorecidas socialmente.

O hábito de tomar banho no Brasil possui peculiaridades características da formação do país, que tem a ver com a ampliação do povoamento, por diferentes culturas, que foi iniciado a partir da chegada dos portugueses. Diferentes dos espanhóis em outros países da América Latina, os portugueses chegaram ao Brasil em menor número e com menos pretensões, não encontraram riquezas e metais preciosos como nos impérios asteca, inca e maia. As sociedades indígenas aqui estabelecidas acabaram influenciando os hábitos dos portugueses principalmente pelo grande número de casamentos entre homens europeus e mulheres indígenas que aconteceram na época. Estes casamentos eram convenientes para Portugal e aconteceram pela intenção de povoar a nova terra, pois não haviam mulheres portuguesas nas primeiras expedições. Estas índias recémconvertidas e batizadas pelos padres jesuítas, foram as mães da primeira geração de mestiços entre europeus e indígenas, e assim passaram para seus descendentes hábitos de higiene, como limpeza corporal com banhos diários, que era seu costume tropical (FREYRE, 2006).

A atividade de tomar banho, diferente de outras atividades cotidianas, vai além do resultado objetivo da remoção da sujeira corporal (CHEUNG et al., 2009; SHOVE, 2003). Ao analisar os hábitos no Reino Unido, Shove (2003) lista algumas motivações para a prática que vão além da limpeza do corpo. Existe a questão do significado social, sendo que por muito tempo o banho foi um marcador social de status de elite. Por outro lado, é necessário banhar-se para estar inserido na sociedade dita civilizada. Também existem questões terapêuticas, como o relaxamento e as propriedades curativas da imersão na água. Existe também o sentimento de prazer e ao mesmo tempo dever (de manter o corpo limpo) que envolve a atividade. A facilidade de ter banheiros com duchas e banheiras dentro dos lares tem possibilitado o aumento da frequência e duração dos banhos, que são vistos hoje como essenciais para a higiene corporal e manutenção da saúde física (SHOVE, 2003). Dessa forma, com a difusão dos hábitos de limpeza e higiene para cada vez mais pessoas, o consumo de água e também de energia se elevou.

Os debates sobre a definição do que seria o uso racional da água e energia no hábito de tomar banho via de regra centram-se na definição de indicadores de consumo. Neste aspecto Cheung et al. (2009) argumentam que o consumo de água durante um banho pode ser menos que 9 litros, que serão atingidos com um banho três minutos de duração, que é o tempo de molhar-se, ensaboar-se e retirar o sabão, desde que o chuveiro não fique aberto desnecessariamente. Porém é comum que muitas pessoas gostem de tomar banhos demorados, o que deixa de ter relação com a necessidade de higienização corporal. O banho por esse lado pode ser considerado um momento de relaxamento, onde o contato com a água ajuda o indivíduo a desligar-se do stress da vida 
contemporânea (CHEUNG et al., 2009). Neste sentido os autores chamam a atenção para a importância da consciência do usuário nesse momento, sendo que um único banho de 15 minutos pode consumir mais do que 135 litros de água (dependendo da vazão do chuveiro), o que é mais do que o consumo médio diário de muitas famílias. Dessa forma, é necessário compreender como acontecem as mudanças sociais que levam a mudanças no consumo.

Para entender como um comportamento se torna um hábito é fundamental para entender o aumento ou alterações no consumo. Shove (2003) procura compreender as mudanças que vem acontecendo nos conceitos de conforto, limpeza e conveniência a partir da lavagem de roupas, banho e conforto térmico. No Reino Unido (onde foi realizada a pesquisa) o consumo doméstico de água subiu $70 \%$ nos últimos trinta anos, sendo que tomar banho e lavar roupas representam um terço desse consumo. Além disso, a frequência dessas práticas aumentou cinco vezes ao longo do último século (SHOVE, 2003). O que está diretamente relacionado a percepção de limpeza, conforto e conveniência tidos como convenções atualmente.

Como o conceito de limpeza no Brasil atualmente é um sinal de valor pessoal (BARBOSA, VELOSO, 2014), esse fundamento cultural leva as pessoas a darem mais importância a isto do que aos gastos de recursos decorrentes do seu uso. Como tratam-se de hábitos enraizados na vida das pessoas, as implicações para a sustentabilidade podem ser preocupantes. Para Barbosa e Veloso (2014) a mudança desses hábitos exige muito mais do que divulgação dos conceitos de sustentabilidade e campanhas de conscientização. As autoras destacam que por mais que as pessoas compreendam os conceitos, com o tempo os seus hábitos enraizados prevalecerão.

É possível perceber por meio das informações apresentadas que os conceitos de limpeza e higiene foram sendo modificados socialmente na sociedade, tanto por meio de descobertas sobre boas práticas, quanto por fatores sociais. Essa idealização de limpeza mostra-se como um dos fatores que influenciam o ato de tomar banho como acontece hoje no Brasil. Além disso, como mostrado no texto, o banho possui unidades de satisfação que vão além da questão da limpeza corporal, o que também necessita ser investigado para que seja possível determinar a influência dessas outras funções no consumo de água e energia.

\section{Limites e Contradições para um Consumo Sustentável}

Hábitos podem ser um dos principais desafios na construção de uma sociedade sustentável. Na maior parte das famílias brasileiras é mais importante não quebrar a "lógica da poluição" (BARBOSA, VELOSO, 2014) do que poupar recursos como água e energia. Essas barreiras e contradições interferem nos avanços em direção ao design sustentável, pois estão relacionadas a conceitos simbólicos que foram culturalmente construídos na sociedade atual. A lógica da "limpeza perfeita" e do "quanto mais água, melhor" contradiz as ideias relacionadas aos estilos de vida mais sustentáveis (BARBOSA, VELOSO, 2014). Isto acontece porque muitas vezes, estas práticas acabam consumindo mais recursos do que seria necessário para realizar atividades de limpeza, tanto de ambientes quanto higiene pessoal.

Shäfer, Jaeger-Erben e Santos (2011) destacam que a maioria das pessoas praticam o que eles chamam de "comportamento de patchwork", sendo que em alguns sentidos tem atitudes sustentáveis enquanto em outros continuam gerando muitos impactos. Isenhour (2011) também destaca essas contradições, sendo que muitas vezes, as pessoas desejam ter atitudes sustentáveis, 
mas os incentivos de campanhas governamentais e pesquisas são impraticáveis em alguns sentidos. Isto acontece por não se considerar que certos hábitos são provenientes de padrões culturais que posicionam os indivíduos na sociedade, as pessoas podem estar dispostas adotar alguns hábitos, porém outros podem ir contra seus valores. Os hábitos cotidianos que envolvem noções de limpeza e símbolos de status e prestígio costumam estar entre estes, que em conjunto com o sentimento de que "isto não é o meu problema" dificultam as atitudes sustentáveis (BARBOSA, VELOSO, 2014). Assim, a responsabilidade pelo consumo é outro fator que pode influenciar e dificultar a difusão da sustentabilidade.

Outra barreira para a difusão das preocupações ambientais entre toda a população é o fato dos moradores de grandes centros urbanos viverem completamente afastados da natureza. As questões ambientais não fazem parte do seu dia-a-dia, sendo vistas como questões externas, transmitidas pelos meios de comunicação e tecnologias, isto resulta em uma miopia cognitiva. Assim, um envolvimento maior com a natureza poderia trazer as pessoas maior engajamento em estilos de vida sustentáveis. Para acessar informações sobre problemas ambientais as pessoas que moram em grandes centros urbanos que não tem contato direto com os efeitos causados pelo seu consumo precisam recorrer a análises técnicas, como análises de ciclo de vida, cálculos de pegada de carbono, etc. Dessa forma a dependência dessas informações, dificulta a relação dos indivíduos (e seu consumo) como causa dos efeitos ambientais apresentados nessas análises (ISENHOUR, 2011).

Enfrenta-se atualmente um dilema em relação ao consumo, enquanto o aumento das comodidades por meio do acesso ao consumo é um objetivo de grande parte das pessoas, corporações e governos, também é a causa de riscos ambientais, de saúde e igualdade. O aumento no consumo também diz respeito ao acesso de cada vez mais pessoas, que vem ascendendo economicamente aos bens oferecidos pela indústria e tecnologia. Barrar esse aumento seria impedir que pessoas do mundo todo tenham uma vida mais confortável e igualitária. Porém, o planeta não dispõe de recursos infinitos e não pode atender a demanda por crescimento que existe hoje (O’ROURKE, LOLLO, 2015). Dessa forma a busca pela equidade social implica em uma contradição entre os âmbitos social e ambiental da sustentabilidade e é necessário pensar em formas de promover o acesso aos bens sem que isso acabe por impactar ainda mais na sustentabilidade do planeta.

Um dos maiores desafios para promover o consumo sustentável, tanto em países emergentes quanto em países desenvolvidos, é tornar o estilo de consumo sustentável atraente o suficiente para tomar o lugar do estilo de vida altamente consumista que tem sido difundido pela mídia e almejado principalmente pelos mais pobres. Em muitas áreas do desenvolvimento de produtos (nutrição, habitação, móveis, roupas, cosméticos, eletrodomésticos) já se encontram muitas soluções seguindo padrões de sustentabilidade. Porém existem tendências que compensam negativamente essas soluções em produtos, como a expansão da população urbana, aumento das possibilidades de deslocamento e mobilidade devido a globalização, demandas por espaço, devido ao crescimento populacional, etc. que caracterizam o efeito rebote (SHÄFER, JAEGER-ERBEN, SANTOS, 2011). O efeito rebote acontece quando há uma compensação da sustentabilidade adquirida com medidas de eficientização tecnológica. Estratégias de redução são implantadas, mas em contrapartida o consumo aumenta devido a outros fatores sociais. "à maior eficiência energética dos dispositivos eletrônicos domésticos foi compensada, ou mesmo (super) compensada, por um aumento das famílias que possuem esses bens" (SCHÄFER, JAEGER-ERBEN, SANTOS, 2011 p. 180). 
Por isso é necessário que as medidas para um consumo sustentável envolvam os usuários, motivando escolhas sustentáveis e estilos de vida menos impactantes ambientalmente.

Os ganhos em eficiência de sistemas podem estar sujeitos a efeitos rebote, pois, este aumento da eficiência pode levar a um aumento do uso que leva a um aumento no consumo, que podem comprometer os ganhos iniciais. Estima-se que que os efeitos rebote podem limitar os benefícios da implantação de sistemas eficientes a $60 \%$ dos potenciais teóricos. A renda economizada em um setor pode ser convertida em aumento de consumo em outros setores, mascarando a real situação apresentada. Dessa forma, essa inicial eficiência, pode acabar acarretando em problemas ambientais de outros níveis (O'ROURKE, LOLLO, 2015).

O'Rourke e Lollo (2015) apontam estimativas de crescimento populacional podendo chegar a 9,6 bilhões em 2050 e 11 bilhões em 2100. Este aumento da população implica em um drástico aumento do consumo global de recursos. Os países desenvolvidos até então, foram os principais responsáveis pelo consumo, sendo que os EUA possuem $4 \%$ da população e $20 \%$ das emissões de gases que causam efeito estufa, o que corresponde a quatro vezes mais que a China que tem uma população bem maior. Porém, estima-se que uma grande parte das emissões no futuro virão de países emergentes. Dessa forma o crescimento populacional é outra significativa barreira a ser considerada para o consumo sustentável de recursos do planeta.

Conforme apresentado, percebe-se a necessidade de combinar inovações tecnológicas, que considerem mudanças a longo prazo, para possíveis cenários de escassez futuras. Além disso, o papel do comportamento de consumo das pessoas também requer um estudo aprofundado, de modo a possibilitar o desenvolvimento de soluções em direção à hábitos de consumo sustentáveis. O governo também pode contribuir com medidas e normas legislativas que direcionem mudanças de comportamento. Além disso, olhar para as populações de baixa renda e facilitar o seu acesso a produtos e serviços mais sustentáveis também se mostra necessário.

\section{Considerações Finais}

Este artigo procurou contribuir com informações a respeito dos hábitos de consumo em contextos de baixa renda, principalmente as Habitações de Interesse Social (HIS). O enfoque foi demonstrar como convenções sociais e valores determinados pelas condições culturais levam a formação de hábitos de consumo. Utilizou-se o hábito de tomar banho para exemplificar como os valores relacionadas a limpeza e a higiene implicam no consumo de água e energia e devem ser considerados por designers e outros profissionais no desenvolvimento de produtos mais sustentáveis.

Foi possível obter por meio deste artigo, uma visão geral acerca das possibilidades de transição para um consumo mais sustentável, principalmente no que diz respeito a um leap frogging de forma que as populações de baixa renda possam aumentar seu acesso aos bens de consumo de forma mais consciente. É possível perceber que os desafios neste sentido são amplos, visto que foi identificada a tendência a uma emulação dos hábitos de consumo de camadas sociais mais abastadas financeiramente (SLATER, 2002) que apresentam muitas vezes comportamentos de desperdício. Além disso, outros fatores como efeitos rebote, afastamento da natureza e a própria dificuldade em tornar o consumo sustentável tão atraente quanto o tradicional são barreiras que 
devem ser pensadas e discutidas em áreas multidisciplinares.

Pessoas de baixa renda, moradoras de HIS, constituem grande parte da população do Brasil e de outros países com características econômicas semelhantes, por isso, medidas voltadas a estas populações podem ser de grande contribuição tanto para o âmbito ambiental da sustentabilidade quanto para o social. Quanto ao âmbito econômico da sustentabilidade, o grande número de pessoas que pode ser atingida por soluções deste tipo, pode ser economicamente interessante para empresas, que poderão materializar soluções mais assertivas. Além disso, este estudo abre caminhos para que novos modelos de negócio, baseados em serviços possam ser criados, auxiliando na concretização das ideias desenvolvidas e trazendo benefícios econômicos para empresas, usuário e meio ambiente.

Os objetivos propostos inicialmente para este artigo foram alcançados, de modo que foi possível evidenciar informações base para o desenvolvimento de produtos e serviços. Porém observa-se que ainda são necessários outros estudos, de caráter aplicado, para fornecer informações concretas a respeito dos hábitos de consumo apresentados. De acordo com as informações apresentadas neste artigo, é necessário considerar cada grupo de usuários de forma individual, pois as características culturais e sociais variam conforme variam os valores e crenças das populações envolvidas. Assim, esta pesquisa encontra-se em desenvolvimento, sendo que o próximo passo consiste no levantamento de informações em campo, junto aos usuários para coletar dados que possam agregar as informações aqui apresentadas.

\section{Referências}

BARBOSA, Lívia. Sociedade de consumo. Rio de Janeiro: Jorge Zahar. Ed. 2004.

; Os Donos e as Donas da Cozinha. In: Maria Ester de Freitas; Marcelo Dantas. (Org.). Diversidade Sexual e Trabalho. 1ed.São Paulo: CENGAGE Learning, 2011, v., p. 171-201

; VELOSO, Leticia. Consumption, domestic life and sustainability in Brazil. Journal of Cleaner Production, Elsevier, 63, 2014. p. 166 - 172.

CARDOSO, Rafael. Design para um mundo complexo. Cosac Naify. Rio de Janeiro, 2012.

CARRETE, Lorena. et. al. Green consumer behavior in an emerging economy: confusion, credibility, and compatibility. Journal of Consumer Marketing, Vol. 29, 7, 2012. p. 470 - 481.

CHEUNG, Peter Batista; et al. Consumo de água. In: GOLÇALVES, Ricardo Franci, et al. Conservação de água e energia em sistemas prediais e públicos de abastecimento de água. Rio de Janeiro: ABES, 2009

CHIKWECHE, Tendai; STANTON, John; FLETCHER, Richard. Family purchase decision making at the bottom of the pyramid. Journal of Consumer Marketing, v. 29, n. 3, p. 202-213, 2012.

CONSUMO SUSTENTÁVEL: Manual de educação. Brasília: Consumers International/ MMA/ MEC/ IDEC, 2005. $160 \mathrm{p}$

DOUGLAS, Mary. Pureza e perigo: ensaio sobre a noção de poluição e tabu. Perspectiva, São Paulo: Debates, v. 120, 2010. 
FEDERAL, Caixa Econômica. Caixa Econômica Federal. Diretoria de Parcerias e, 2018. Disponível em:

<www1.caixa.gov.br/gov/gov_social/municipal/programas_de_repasse_do_OGU/habitacao_inter esse_social.asp>. Acesso: 15/03/2018.

FREYRE, Gilberto. Casa-Grande \& Senzala. 51ạ. São Paulo: Editora Global, 2006.

FORTY, Adrian. Objetos de desejo. Editora Cosac Naify, 2007.

ISENHOUR, Cindy. Can Consumer Demand Deliver Sustainable Food? Environment and Society, v. 2, n. 1, p. 5-28, 2011.

O'ROURKE, Dara; LOLLO; Niklas. Transforming Consumption: From Decoupling, to Behavior Change, to System Changes for Sustainable Consumption. Annual Review of Environment and Resources, vol. 40, 2015. p. $233-259$

SCHÃFER, Martina; JAEGER-ERBEN, Melanie; SANTOS, Aguinaldo dos. Leapfrogging to Sustainable Consumption? An Explorative Survey of Consumption Habits and Orientations in Southern Brazil. In: Journal of Consumer Policy, Econpapers, vol. 34, 2011. p. $175-196$

SHOVE, Elizabeth. Converging Conventions of Comfort, Cleanliness and Convenience. In: Journal of Consumer Policy. 26, 2003, p. $395-418$.

SLATER, Don. Cultura do Consumo e Modernidade. In: Cultura do Consumo \& Modernidade. São Paulo: Nobel, 2002. pp. 17-39. 